\title{
A Novel Method for the Determination of Exostosis Severity in the External Auditory Canal
}

Mike Climstein $^{1}$, Vini Simas ${ }^{2}$, Mark DeBeliso ${ }^{3}$, and Joe Walsh ${ }^{4}$

${ }^{1}$ Southern Cross University - Gold Coast Campus

${ }^{2}$ Bond University

${ }^{3}$ Southern Utah University

${ }^{4}$ Sports Science Institute

January 5, 2021

\begin{abstract}
Guidelines state there is no Abstract for Correspondence: Our Experience
\end{abstract}

\section{Hosted file}

COA-2020-1094 Determination of exostosis_a novel method.pdf available at https://authorea. com/users/387460/articles/502531-a-novel-method-for-the-determination-of-exostosisseverity-in-the-external-auditory-canal

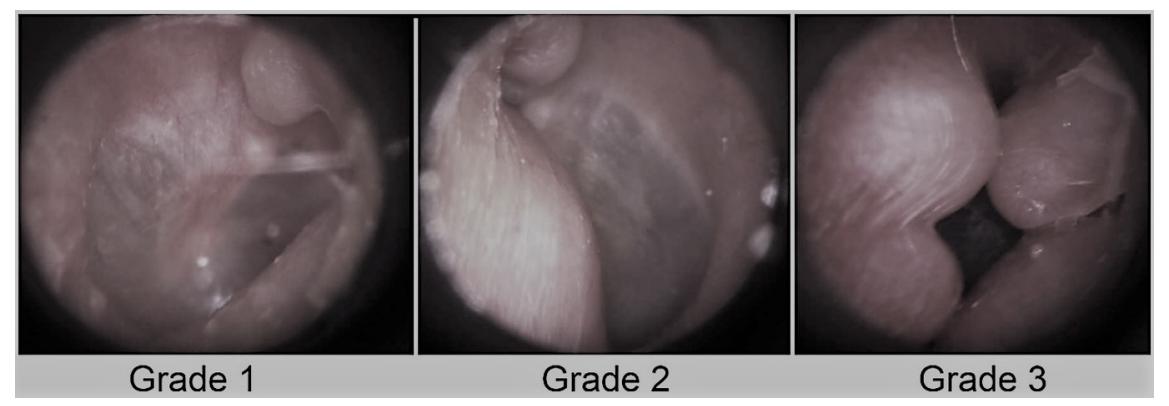



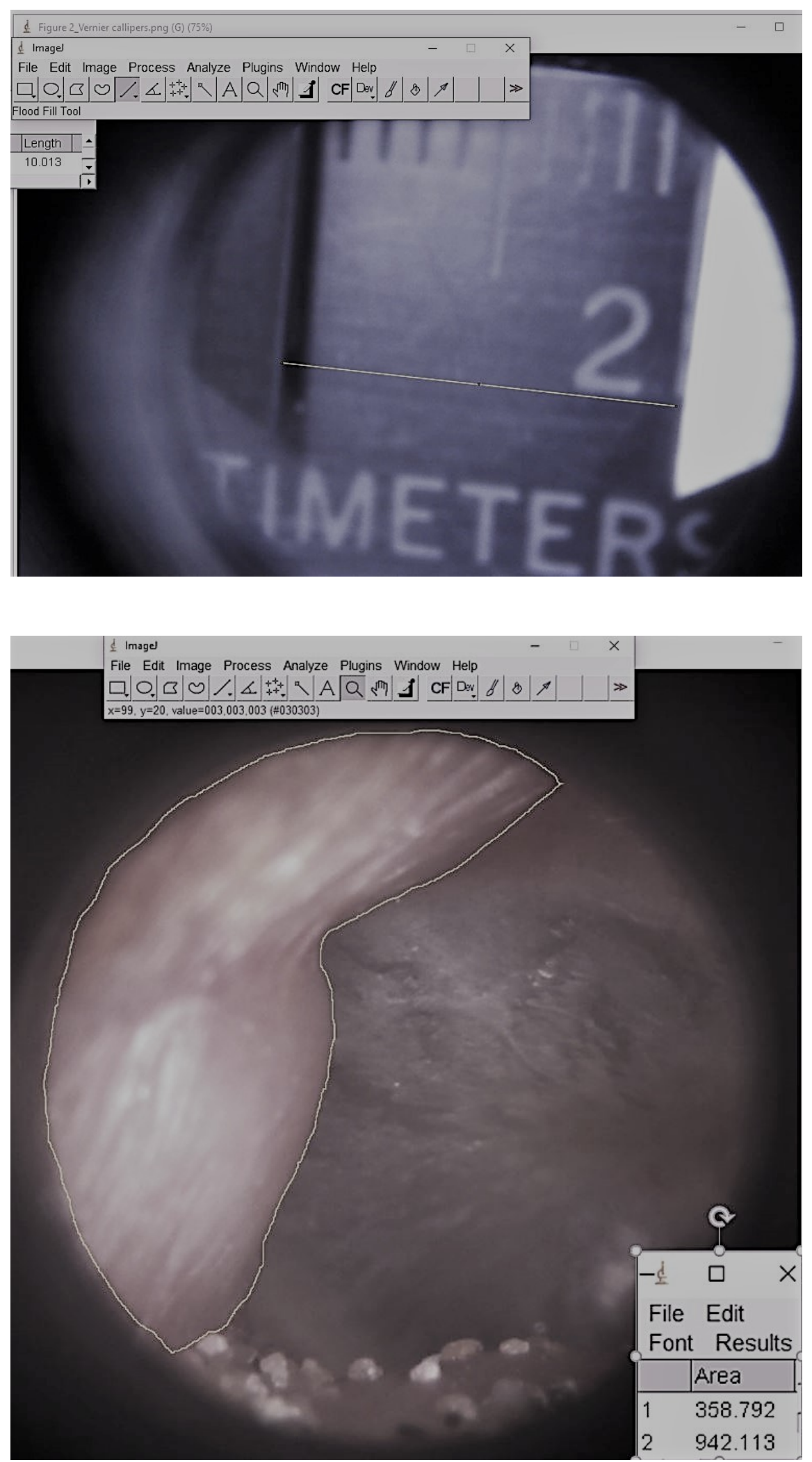